\title{
The Instrumentation and monitoring of the Vårby Bridge
}

\author{
Mattias NILSSON \\ Bridge Engineer, M.Sc. \\ Ramböll Sverige AB/LTU \\ Luleå, Sweden \\ Mattias.nilsson@ramboll.se \\ Peter COLLIN \\ Professor \\ Ramböll Sverige AB/LTU \\ Luleå, Sweden \\ Peter.collin@ramboll.se
}

\author{
Kjell ERIKSSON \\ Associated Professor \\ Luleå Univ. of Tech (LTU) \\ Luleå, Sweden \\ Kjell.eriksson@ltu.se
}

\author{
Gerard JAMES \\ Consulting Engineer, Ph.D \\ Projektengagemang AB \\ Stockholm, Sweden \\ Gerry.james@glocalnet.se
}

\section{Summary}

Numerous cracks have been discovered in the Vårby Bridge near Stockholm, Sweden. All cracks are found at the junctions between the cross girders and the main girders, more specifically, at the welds connecting the vertical web stiffeners to the top flanges of the main girders. The cracks might possibly be causing serious problems if they are allowed to propagate through the entire length of the weld, thereby permitting out-of-plane bending of the main girder web. In order to identify the reason for the observed cracks, an ongoing investigation under the commision of the bridge owner was started in the spring of 2009. One conclusion so far, is that the observed cracks conclusively are a result of fatigue

As a part of a master thesis, FEM-modelling is currently under way. As the fatigue process is distortional, the propagation phase of the observed cracks might slow down or even stop. One task will be to determine the stress intensity factor versus crack length relationship in order to model a growing crack. The final chosen method of refurbishment will be based upon the results of the study and will be implemented in cooperation with the bridge owner.

Keywords: fatigue, steel, composite bridges, design, bridge measurements, maintenance, distortion, fracture mechanics, FE-modelling, fatigue tests,

\section{Introduction}

In the summer of 2006 during a routine inspection of the Vårby bridge, numerous cracks were found [1]. Generally, all the cracks occurred at the junctions between cross girders and the main girders, specifically at the welds connecting the vertical web stiffeners to the top flanges of the main girders. All the cracks were located in the spans of the bridge, i.e. at cross girders with a single one side vertical main girder web stiffener, and none were observed at the supports (where the web of the main girders is fitted on both sides with stiffeners).

The reason for the observed cracks was believed to be secondary effects of restraint when the rigid concrete deck is rotating above the main steel girders.
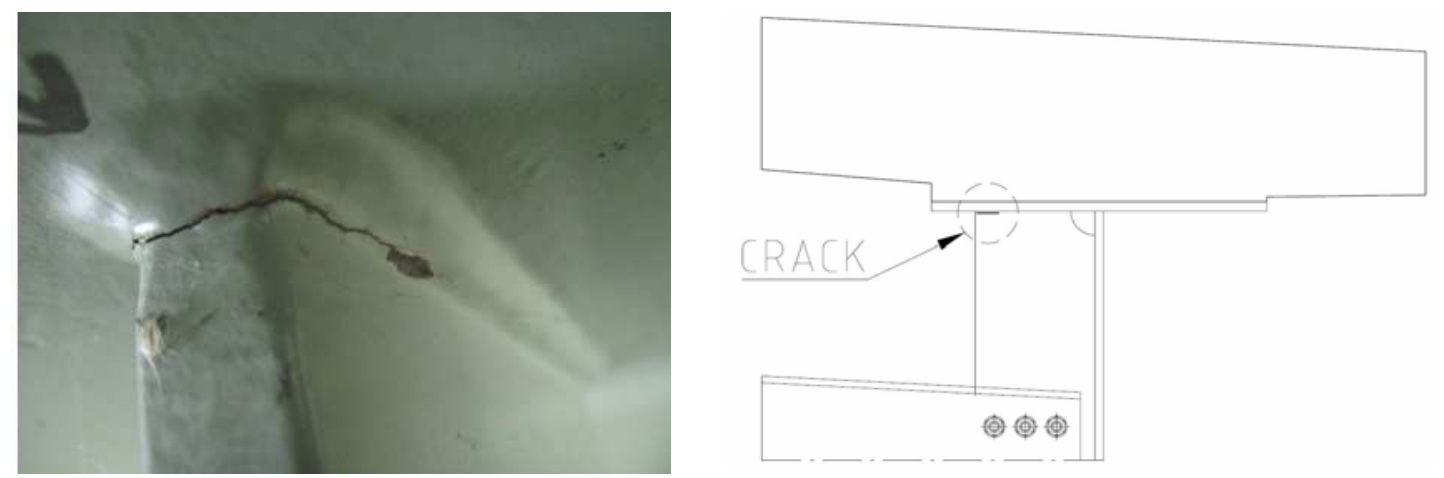

Fig. 1: One of the observed cracks 
In order to identify the reason and the potential danger of the cracks, an investigation under the commission of the bridge owner - Vägverket Region Stockholm - was started in the spring of 2009. In an investigation of this kind, there are a number of key questions to be answered

- What is the cause of the observed cracks?

- Why do the cracks occur in this particular bridge?

- Are there any immediate concerns regarding the durability and safety of the bridge?

- How can the problem be solved?

From a more general point of view, further questions are raised

- Can we expect this type of damage in other existing bridges?

- What can be done to prevent this type of damages in the future?

\subsection{A possible cause of the observed cracks}

A possible cause for the observed cracks is secondary effects of restraint when the rigid concrete deck rotates above the main steel girders.

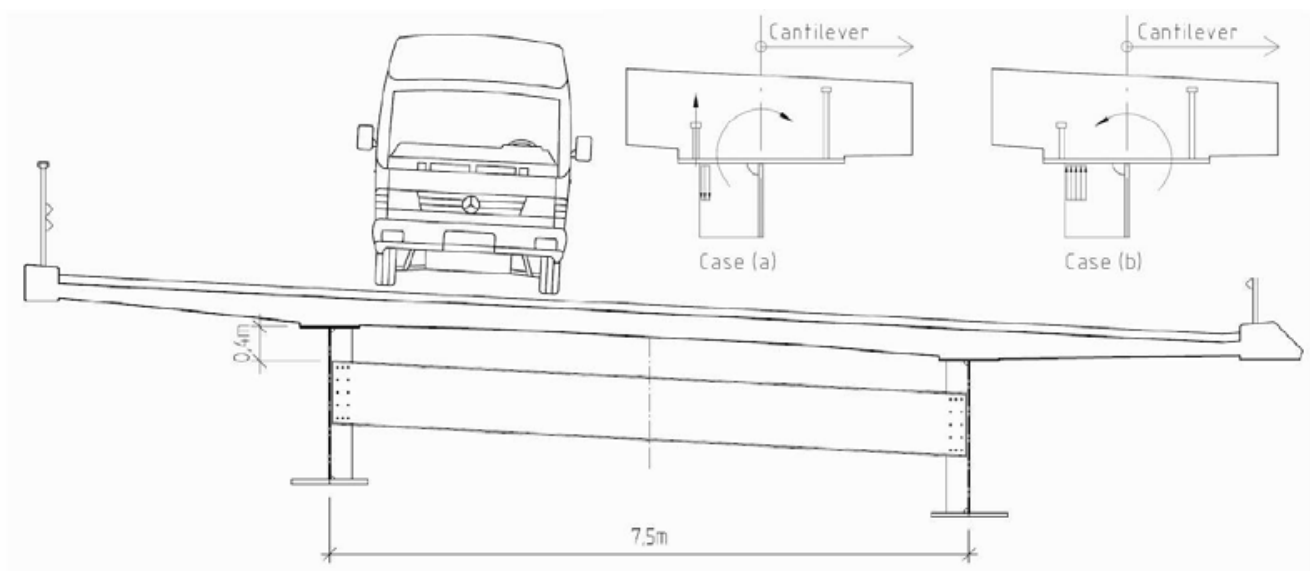

Fig. 2: Interaction between steel girders and concrete deck for transverse rotation

Between cross girders, only the top flange of the main girders provide ridigity against the rotation of the bridge deck. This rigidity is limited and the bridge deck can, in this case, be idealized as simply supported on the two main girders. However at a cross girder connection, the rotation of the deck will experience some restraint depending of the deformability of the bracing member. Fig. 2 illustrates the interaction between the deck and the main girders as the deck is rotating. When a heavy vehicle is situated on the cantilever part of the deck, the hogging moment causes a tensile force to be transferred via the shear connectors through the particular weld and further into the single vertical stiffener, see Case (a) in above figure. When a heavy vehicle passes in between the two main girders, hence producing a rotation of opposite sign, compressive forces act on the stiffeners and the welds, see Case (b) in above figure. The algebraic difference between the tensile and the compressive forces governs in turn the nominal normal stress range in the observed crack plane, a critical parameter for fatigue crack growth in a weld.

It is worth mentioning that the distance between the two main girders, 7,5 m, is large compared to other compatible composite bridges in Sweden. Furthermore, as the cross girders were used for carrying the wet concrete during the casting of the deck, the cross girders are relatively rigid and are located rather close to the top surface of the main girders.

The investigation includes in-situ monitoring of strains and displacements in the bridge as well as fractographic examinations of extracted crack surfaces.

\subsection{A first simple FEM-model}

A first step in order to investigate the reason behind the cracks occurring at the Varby Bridge was to develop a simple FEM-model. Both shell elements and ordinary beam elements. 


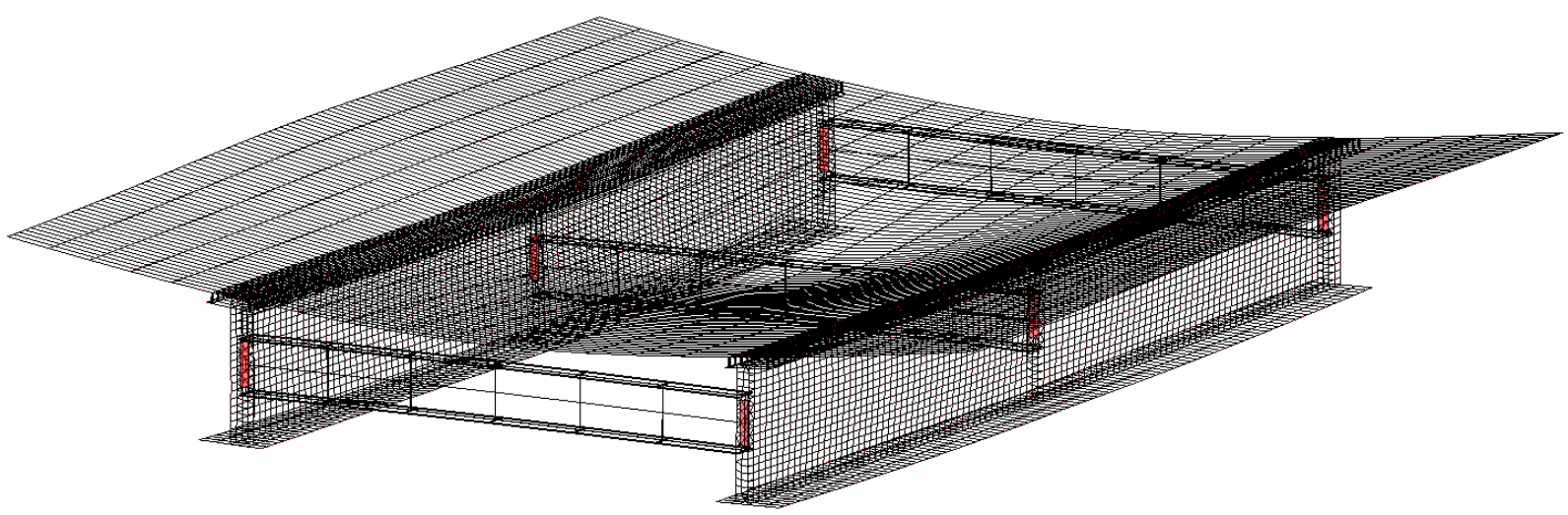

Fig. 3: FEM-Model

The significant stresses in the stiffener were found to be of very local extent, indicating a significant stress concentration centered at the outer edge corner of the stiffener. As the width of the actual welds connecting the stiffeners and the top flanges is $2 \times 5=10 \mathrm{~mm}$, in comparison to the width of the stiffeners, $20 \mathrm{~mm}$, the stress peak in the welds might be up to twice the computed nominal value. The FEM analysis, although simple, closely models the behaviour of the junction and indicates satisfactorily the magnitude of stress in the stiffener at the in-situ measurements locations described in part 2.

\subsection{Observations in other countries}

Similar damages have been observed in other countries as well. The figure below shows examples of cracked welds in an Austrian bridge.
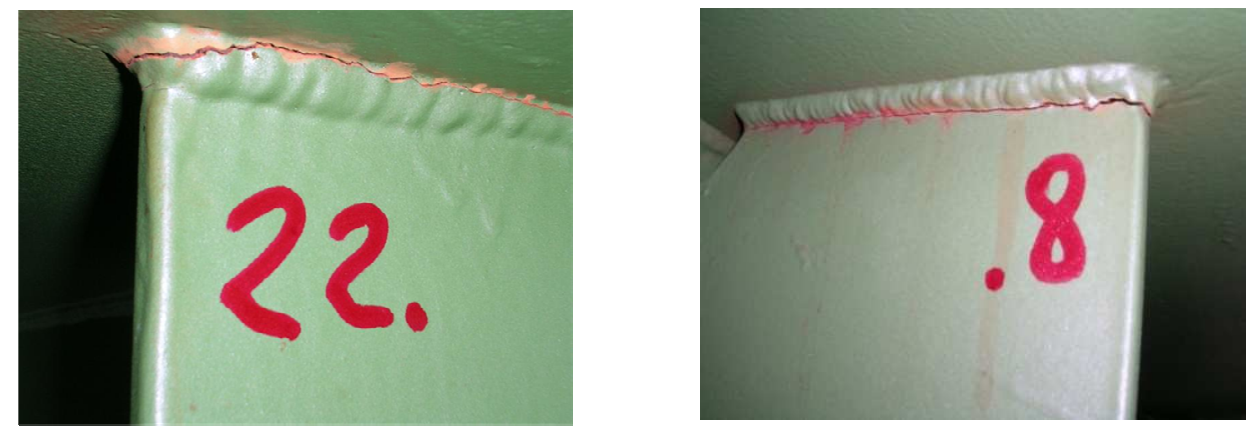

Fig. 4: Cracked welds observed in Austria. From [2]

An investigation [2] under the auspices of ASFINAG - the Austrian highway authorities - has been conducted by Prof. Richard Greiner et al, Graz University of Technology.

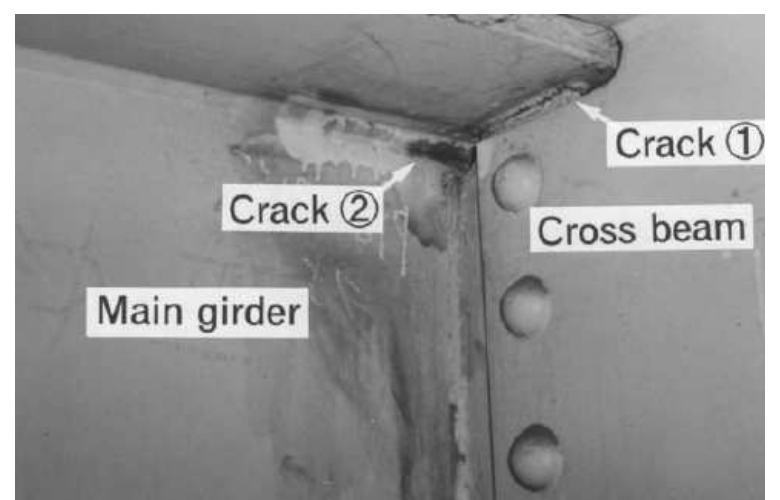

The problem has also been observed in Japan, where in fact, cracks of this kind are the most frequent type [3].

Crack no. 1 occurred at the top of a vertical stiffener welded to the upper flange of the main girder and crack no. 2 at the weld between the web and the top flange of the of the main girder.

Fig. 5: Cracked welds observed in Japan. From [3]

The latter crack in fig. 5 appeared after the first crack (no. 1) had penetrated the top end weld of the 
vertical stiffener completely, hence separating the vertical stiffener from the top flange of the main girder. This is one of the most severe possible problem associated with the kind of cracks observed at the Vårby Bridge.
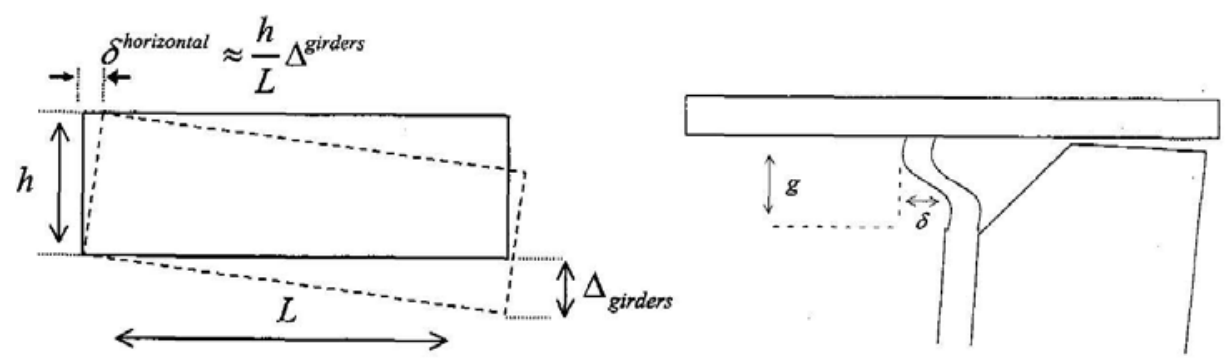

Fig.6: Out-of-plane bending. From [5]

Assuming that a relative deflection $\Delta$ of the adjacent main girder corresponds to a horizontal displacement $\delta=h^{*} \Delta / \mathrm{L}$ as the diaphragm rotates, figure. 6 . An approximate expression for the outof-plane stress in the web gap can be derived, as the un-stiffened part of the main girder web can be regarded as a short fixed-fixed beam undergoing a relative end displacement $\delta$

$$
\sigma \approx\left(3 \cdot E \cdot t_{w} / g^{2}\right) \cdot \delta \approx\left(3 \cdot E \cdot t_{w} / g^{2}\right) \cdot(h \cdot \Delta / L)
$$

The above expression is valid only if the lower left corner is totally restrained from out-of-plane movement. In practice the lower flange of the main girder is to some extent flexible for transverse translation. The expression can however be used to estimate the order of the stress arising. It is seen that even a small relative deflection $\Delta$, can cause a considerable bending stress in the web. For the entire superstructure, crack type no. 2 (main girder web - top flange) is therefore significantly more dangerous than the former (stiffener - top flange).

\section{Field measurements on the Vårby Bridge}

Extensive field measurements were carried out on the Vårby Bridge in the early summer of 2009. Strains and deflections were measured with strain gauges, inclinometers and LVDT:s. In addition a steel sample containing a part of a crack surface was extracted from the bridge.

Two types of measurements with different purposes were carried out:

1. Measurements were conducted for a vehicle of known weight and transverse positioning, resulting in vast amounts of data to be used for verification of the FEM-modeling of the corresponding connections.

2. Measurements conducted with ordinary day-to-day traffic for a period of about 4 days, resulting in a load history to provide a damage assessment.
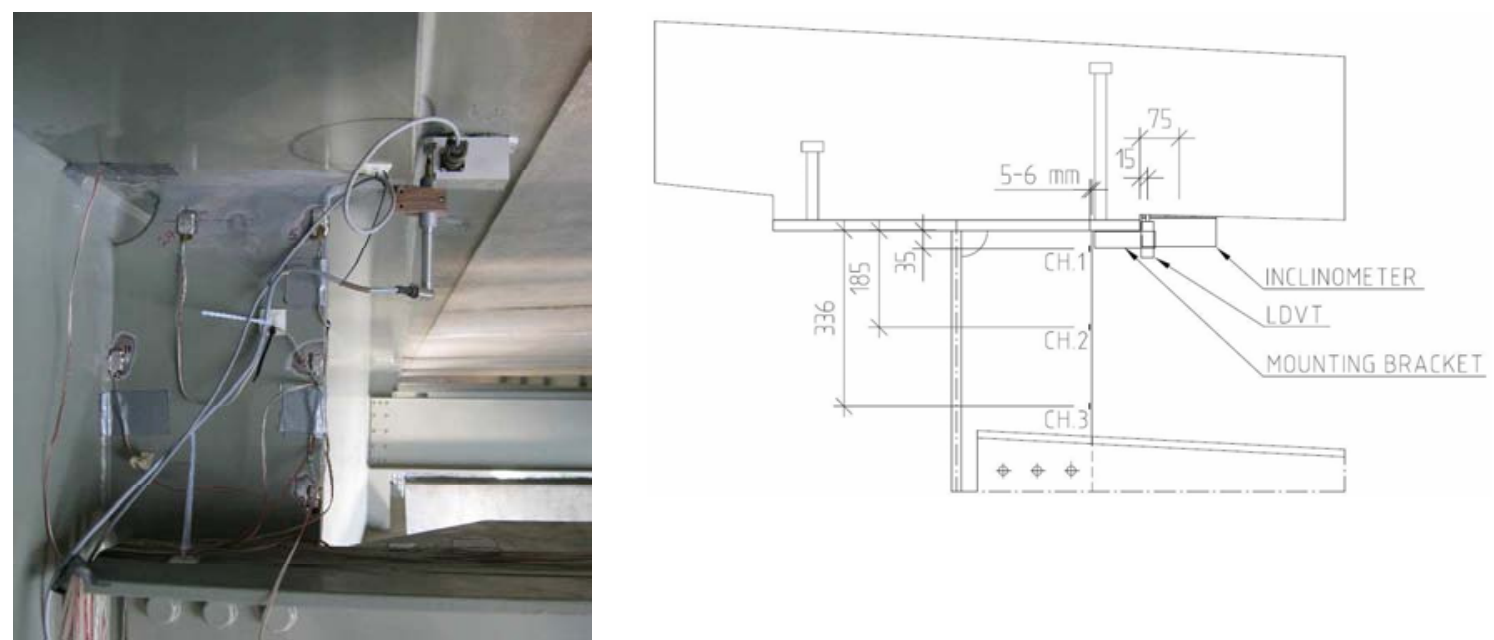

Fig.7: Installed equipment. Positions of gauge no. 1-3 
The relative difference of rotation was also of interest, i.e. the gap opening up between the deck and the top flange of the steel girders as a vehicle passes. For this purpose one LDVT and one inclinometer were installed.

\subsection{Controlled measurements}

The controlled measurements were performed for a vehicle with known weight, speed and position. A total of 21 unique vehicle crossings were monitored during the night between the 5th and 6th of June, 2009. As the the traffic on the bridge is intense, it could not be closed and the measurements were conducted at night. The purpose of the controlled measurements was solely to provide necessary basic data to be used for verification of future numeric models.

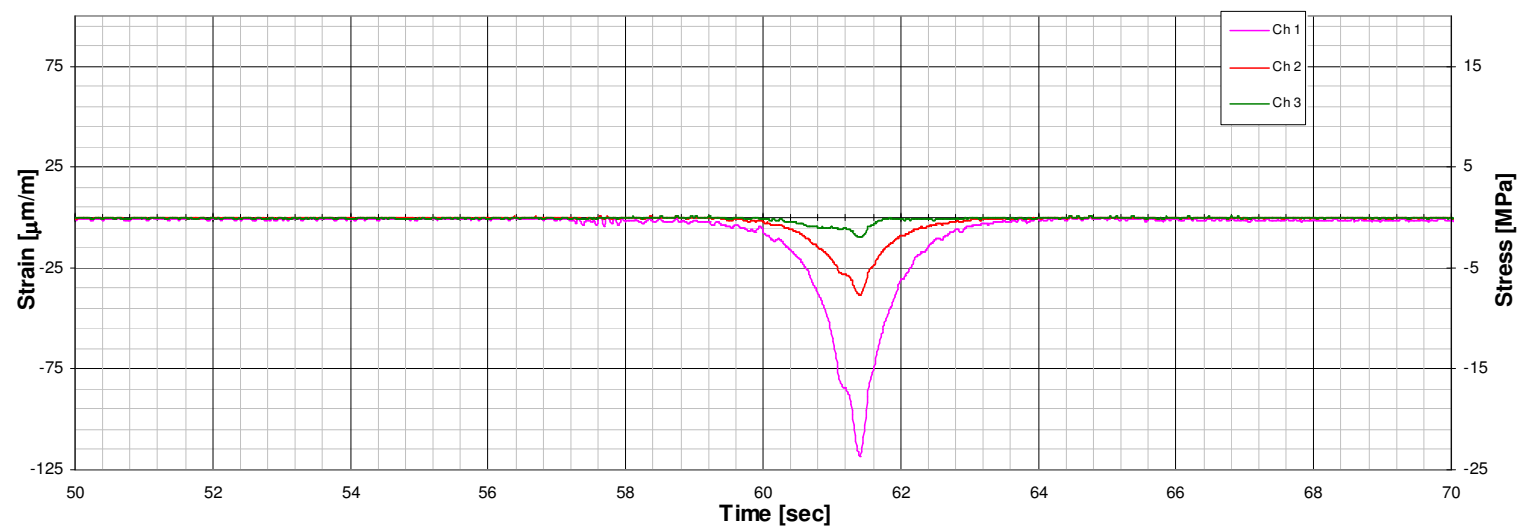

Fig.8: Sample from the controlled measurement (the lowest peak belongs to channel 1)

The most common position of a heavy vehicle on the Varby Bridge is between the two main girders causing compression in the vertical stiffener.

\subsection{Measurements conducted for day-to-day traffic}

To get a clearer understanding of the frequency and the magnitude of the different strains and stresses affecting the particular welds daily, measurements were conducted for ordinary day-to-day traffic for a period of $104 \mathrm{~h}$.
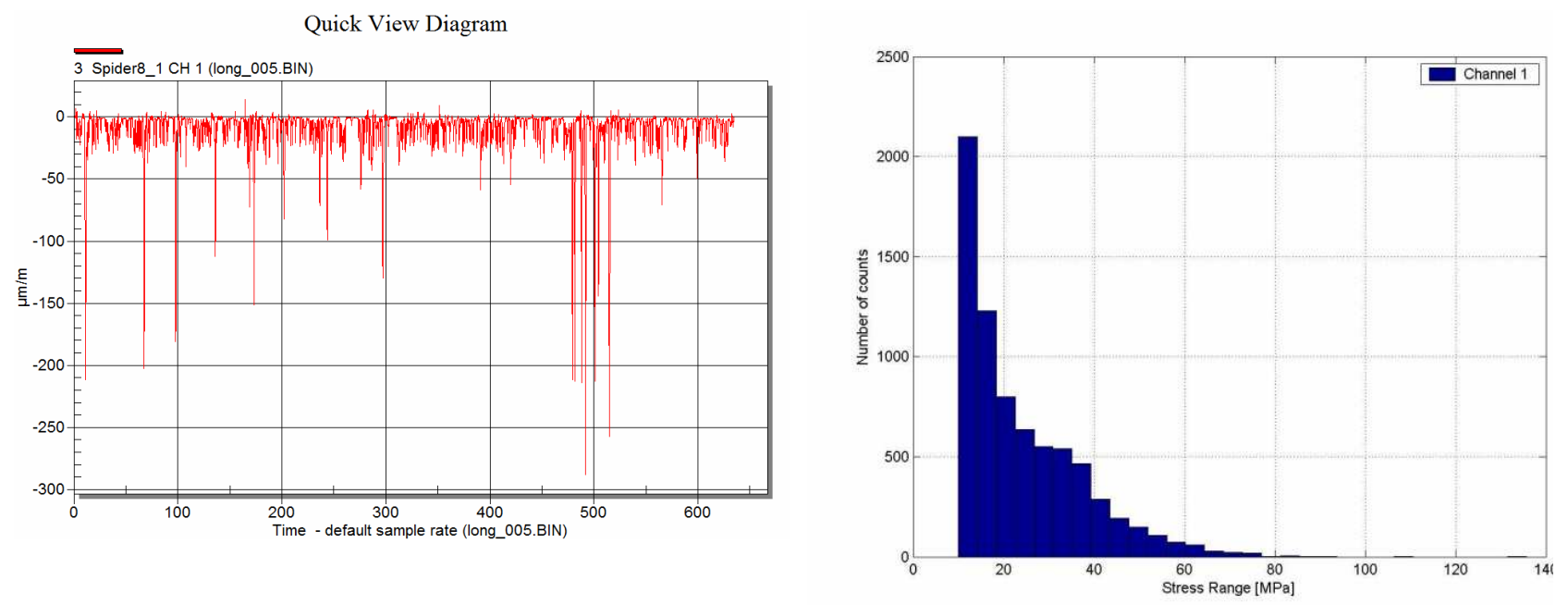

Fig.9: Sample from the day-to-day measurements

Based upon the measured results, Rain Flow-Counting (RFC) analyses were performed creating histograms to be used for damage summation according to the Palmgren-Miner rule. Figure 9 shows an example of the registered strains and the histogram for gauge no. 1. A threshold value was adopted and all stress-ranges $\Delta \sigma<10 \mathrm{MPa}$ were disregarded. Assuming that any present geometric 
stress concentration already is included in the appropriate fatigue category - C36 according to EN 1993-1-9:2005 - the calculated damage was extrapolated over a period of ten years, resulting in a total accumulated damage way above 1.0

Also of interest to compare is the RFC-analyses of gauges no. 5 and no. 19. The former is located at a junction with an undamaged weld and the latter at a corresponding position but the weld is cracked. The two different junctions - connceted to the same main girder - are in all aspects identical and and should therefor endure approximately the same stresses for any given vehicle. This agreement was however not observed, as can be seen in Table 1 . The number of counts is significantly different as the stiffener with the cracked weld endures only $60 \%$ of the counts with $\Delta \sigma>10 \mathrm{MPa}$ compared to the stiffener with the un-cracked weld. The average stress range as well as the maximum stress range are also smaller for the latter.

Table 1.

\begin{tabular}{|l|l|l|}
\hline & \multicolumn{1}{|c|}{ Gauge 5 } & \multicolumn{1}{c|}{ Gauge 19 } \\
\hline *Horizontal distance from edge & $5 \mathrm{~mm}$ & $25 \mathrm{~mm}$ \\
\hline Number of counts & 11744 & 7011 \\
\hline Average stress range & $25.1 \mathrm{MPa}$ & $16.6 \mathrm{MPa}$ \\
\hline Maximum stress range & $120.9 \mathrm{MPa}$ & $50.7 \mathrm{MPa}$ \\
\hline
\end{tabular}

* Horizontal distance from the outer edge of the vertical stiffener.

Gauge no.19 was located ahead of the tip of the crack, about $25 \mathrm{~mm}$ from the outer edge of the stiffener while gauge no. 5 was located only $5 \mathrm{~mm}$ from the equivalent edge. The difference in position together with the obtained data according to table 1, provides a clear indication of a stress concentration centered on the outer edge of the stiffener. The observations could also suggest a more "soft" behaviour as a result of reduced restraint after crack initiation.

\section{Examination of a sample containing a crack}

Parallel to the strain measurements on the bridge, a small steel sample of a weld containing a crack was extracted from the bridge. The sample, which was examined at Lulea University of Technology [6], [7] and [8], was first sectioned into two parts, denoted A and B. Part B was after a first visual inspection expected to contain only a minor surface crack, hence the former was initially given priority.

\subsection{Examination of part A}
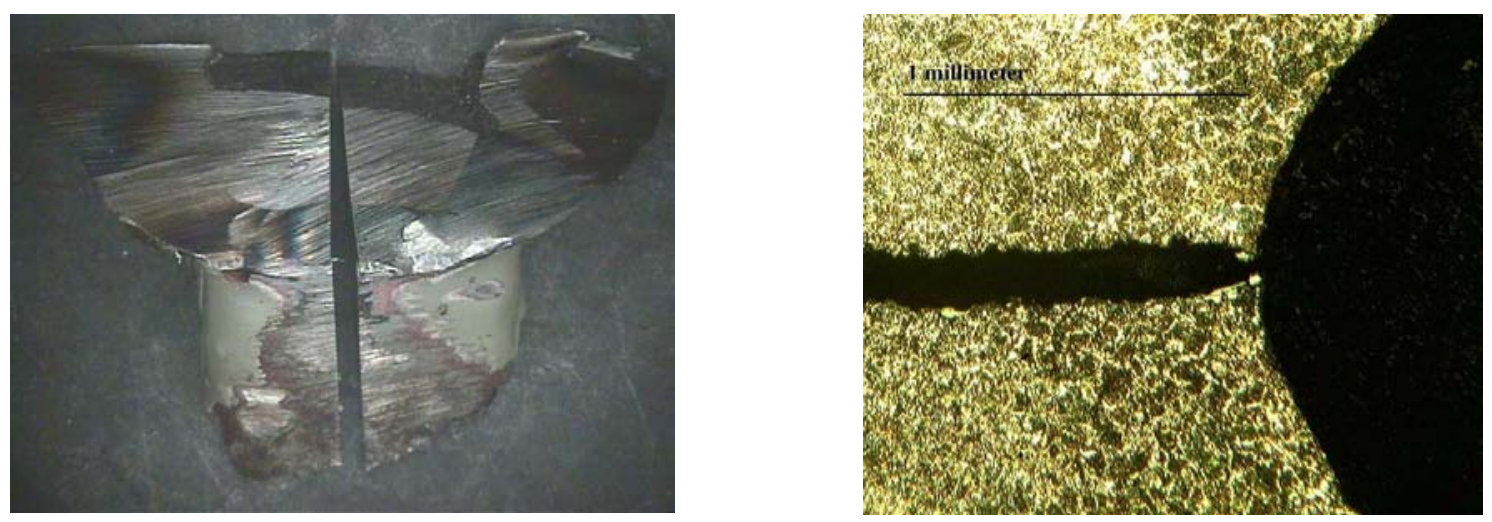

Fig.10: Geometry of the weld

Part A was first examined in an optical microscope. The most important observations are:

- The local weld geometry is irregular and the profile of the weld itself is strongly curved, which features contributing to an intense stress concentration (for stresses perpendicular to the crack plane).

- The initiation and propagation phases of the crack occurred exclusively in weld metal 
- No flaws or other defects in the microstructure of the base metal of the stiffener could be detected and neither in the weld metal nor in the HAZ (Heat Affected Zone). These observations are all excluding faulty material and indicate a geometrical/mechanical reason for the initiation of the crack.

Fractographic methods using SEM (Scanning Electron Microscope) were then used. Due to severe corrosion of the crack surface, the exact location of the area of crack initiation remains uncertain
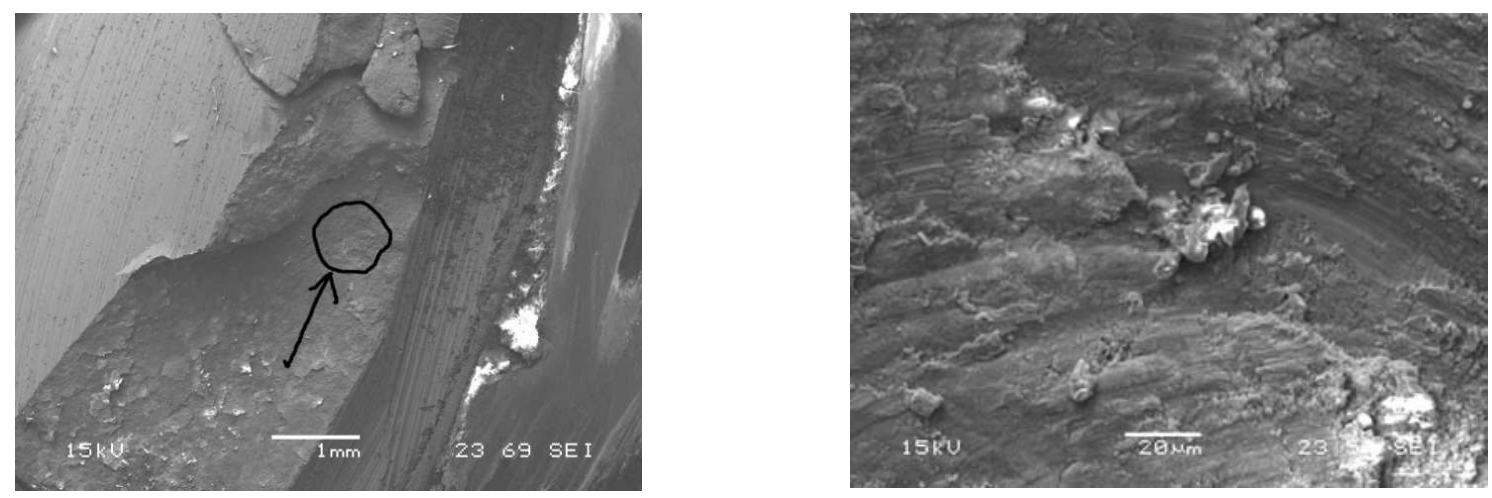

Fig.11: Observed striations

Crack surface striations and "beachmarks", indicating the instantaneous position of the crack front during fatigue crack growth and typical for cyclig loading, could however be observed in certain areas. The distance between consequtive striations at a certain location was found to be within some few $\mu \mathrm{m}$, indicating a considerable propagation rate, which was not compatible with even a small fraction of the service time of the bridge. This and the direction of propagation suggested the idea of two individually initated cracks, merging into one.

\subsection{Examination of part $B$}

As mentioned earlier, part B was initially expected to contain only a minor secondary surface crack. When broken up, an additional, even larger crack in comparison to the former, was found. This observation confirmed the previous assumption of multiple initiation. As the two cracks are approaching each other, the propagation rate accelerates, thus resulting in the closely spaced striations mentioned above.

\subsection{Conclusions based upon the optical and fractographic examinations}

- No defects in the microstructure of the base metal, the weld metal or the HAZ could be found

- The crack initiation and propagation phases occurred exclusivly in the weld metal

- The cause and exact origin of the crack initiation is not completely clear due to severely corroded crack surfaces. Crack initation is not due to faulty material, it is rather caused by geometrical and/or mechanical effects.

- The presence of striations and "beachmarks" on the fracture surfaces indicates unambiguously crack growth through fatigue

- Multiple initiation, i.e. at least two separate cracks has been formed, independently of each other, and have eventually merged into one. The phenomenon of multiple initiation is commonly assosciated with a large number of cycles

\section{Preliminary conclusions}

- The observed cracks are a result of fatigue. This is validated by the result of the performed measurements, damage summations and fractographic examinations.

- The ongoing fatigue process is distortional and a result of the bracing effect of the web stiffeners at each cross girder against the transverse rotation of the slender deck. 
- A significant stress concentration exists at the origin of crack initiation.

\section{Present and future activities}

\subsection{Present activities}

FEM-modelling of the Vårby Bridge is currently going on. The model(s) will be validated using the data gathered during the controlled measurements. The main purposes of the modelling are:

- Evaluate the assumed stress concentration factor at the origin of the observed cracks.

- The ongoing fatigue process is believed to be distortional, causing stresses of restraint in the welds. Thus the propagation phase of the observed cracks might slow down or even stop. One task will be to calculate the stress intesity factor range as a function of the length of an assumed crack in order to investigate conditions for crack arrest, alternatively remaining fatigue life.

Based upon the result of the above, appropriate refurbishment methods will be proposed and discussed with the bridge owner.

\subsection{Future activities}

Future activities will focus more generally on the detailing aspects of similar connections in composite bridges. Full scale component testing in laboratory is also planned. As tests to construct $\mathrm{S}-\mathrm{N}$ curves require a lot of man hours and funding, it is unfortunately not possible within the range of this project. The focus of future research will be to evaluate the interaction between the steel girders, the shear connectors and the concrete deck more rigorously.

\section{Acknowledgement}

The work within the frame of the project described in this paper is carried out with a financial grant from the Research Fund for Coal and Steel (RFCS) of the European Community, granted under the contract No. RFSR-CT-2008-00033.

\section{References}

[1] PROJEKTENGAGEMANG ANLÄGGNING I STOCKHOLM AB "Damage inventory report Knr:2-1701-1 \& 2 Bridge of Vårbyfjärden” (In Swedish, not published)

[2] GREINER R, OFNER R, TARAS A., "Local fatigue failures in highway composite bridges", Paper for Second International Conference on Fatigue and Fracture in the Infrastructure Bridges and Structures of the 21st Century, July 26-29, 2009 Loews Hotel, Philadelphia

[3] KAZUHIRO NISHIKAWA, JUN MURAKO, TAKAYUKI MATSUKI, "Study on the fatigue of steel highway bridges in Japan" Construction and building materials, Vol. 2, Nos. 2-3, 1998 pp. 133-141.

[4] PROJEKTENGAGEMANG ANLÄGGNING I STOCKHOLM AB "Measurement report 101045:2:B "Measurements of strains in vertical web stiffeners and steel main girders. Knr:2-1701-1 \& 2. Bridge of Vårbyfjärden" (In Swedish, not published)

[5] JAJICH D, SCHULTZ A.E, BERGSON P.M, GALAMBOS T.V "Distortion-Induced fatigue in multi-girder steel bridges" Report MN/RC-2000-16. University of Minnesota. Institute of Technology. Department of Civil Engineering.

[6] RUBIN P "Examination of a weld sample containing a crack" Report 090901-342. Rubin Materialteknik (In Swedish, not published)

[7] RUBIN P "Complementary to the examination of a weld sample containing a crack" Report 090921-345. Rubin Materialteknik (In Swedish, not published)

[8] ERIKSSON K "Sample extracted from the Vårby bridge " Report dated 2009-09-10 . Luleå University of Technology. (In Swedish, not published) 